\title{
Risk Factors for Acinetobacter infections in the Intensive Care Unit at King Khalid Hospital- Najran, KSA
}

\author{
Dr. Abdullah Ibrahim Aedh \\ Assistant Professor of Internal Medicine at Najran University, College of Medicine and Internal Medicine \\ Consultant at Najran University Hospital and King Khalid Hospital
}

\begin{abstract}
Acinetobacter are free living gram-negative coccobacilli that emerge as significant nosocomial pathogens in the hospital setting and are responsible for intermittent outbreaks in the intensive care unit. The rising prevalence of Acinetobacter infection in the intensive care units (ICUs) causes a great concern due to their extraordinary ability to develop resistance to multiple classes of antibiotics. The aim of the study was to determine the risk factors for Acinetobacter infections among patients who admitted into the ICU at King Khalid hospital, in Najran, KSA. A total of 160 patients were recruited for this study during the period from Aug. 2016 to April. 2017. Tracheal aspirate, sputum, catheter urine specimen, and blood culture were collected aseptically from the patients. The specimens were cultured on blood agar and Herellea agar and identification of clinical isolates was performed by classical bacteriological techniques. Acinetobacter was isolated in 35 ( 19.4\%) patients . Six (17.14\%) of them were males compared with eight cases (22.86\%) observed among the females. There is no significant difference in the prevalence of Acinetobacter infection between both sexes $(P$-value $=$ 0.460 ). Acinetobacter was isolated from tracheal secretions in 15/35 (42.86\%), followed by sputum 8/35 ( $22.86 \%$ ), wounds 5/35 (14.29\%), central venous line (CVL) 3/35( $8.57 \%$ ), urine 2/35 (5.71\%), and blood 2/35 ( 5.71\%). It was concluded that Acinetobacter is an important nosocomial infection pathogen in the ICU patients due to numerous of factors in terms of patients with old ages, patients with chronic underlying diseases, and in patients that undergoing invasive procedures. Few treatment options are currently available and for this reason, prevention and infection control measures are essential, including antibiotic control strategies in the ICU.
\end{abstract}

Keywords: ICU patients, Acinetobacter, Risk factors

\section{Introduction}

Until 1970, Acinetobacter spp. were considered rare causes of nosocomial infections in the ICU. In recent years, however, the incidence of Acinetobacter infections has reached a point of concern and poses a threat to hospitalized populations around the world. ${ }^{1}$ Acinetobacter are a group of non-fermentative, Gramnegative cocco-bacillus that has emerged as an important nosocomial pathogen. It is a water organism and preferentially colonizes aquatic environments. When Acinetobacter infections occur, they usually involve organ systems that have a high fluid content (eg, respiratory tract, CSF, peritoneal fluid, urinary tract). Besides human skin, Acinetobacter has also been isolated from soil, water, fish, meat, vegetable, hospital air, tap water faucets, sink basins, bed mattresses, bedside urinals and respiratory therapy equipments. ${ }^{2}$ In addition, some reports showed that Acinetobacter colonization and infections occurred more commonly during the warmer and more humid months. Moreover, infections caused by these pathogens in the ICU appeared to be more prevalent in the tropical and subtropical areas such as Australia43and Hong Kong. ${ }^{3}$ Very interestingly, their ubiquitous nature in the ICU environment and inadequate infection-control practice have continuously raised the incidence of Acinetobacter infections over the past two decades. ${ }^{4}$ Acinetobacter is an opportunistic pathogen known for its intrinsic resistance to antibiotics and greater ability to rapidly acquire resistance genes as mobile genetic elements. Acinetobacter is considered to be the most common gram-negative organism colonized on the skin of hospital personnel, including ICU nurses and respiratory therapists. Moreover, transient pharyngeal colonization was noted in $7 \%$ of healthy individuals enrolled in one study. ${ }^{2}$ These findings indicate that hospital personnel and hospitalized patients may be the most important reservoir of this organism. It is increasingly implicated as a cause of healthcare-associated infections (HAI), which confer a high risk of morbidity and mortality to patients. ${ }^{5}$

During the last two decades clinicians in various countries have witnessed a growing number of critically ill patients who suffer from infections due to microorganisms that belong to the Acinetobacter genus, mainly strains of the species Acinetobacter baumannii. ${ }^{6}$ Risk factors for Acinetobacter colonization and infection include prolonged length of hospital stay, exposure to the intensive care unit (ICU), mechanical ventilation, central venous catheterization, urinary catheterization, prior exposure to antimicrobials, greater severity of illness, surgery, and receipt of invasive procedures . Although risk factors for antibiotic resistant $A$. baumannii infection have been explored in many patient populations, fewer studies have assessed potential differences in risk factors for those infected with antimicrobial-resistant versus susceptible strains. ${ }^{7}$ 


\section{Materials and methods}

This study was performed at King Khalid Hospital, a secondary teaching hospital. The study population consists of patients who were admitted in the intensive care unit. A total of 160 patients were recruited into the study, this population of patients comprises of patients who have had surgery, on ventilators or intubation beside prior history of antibiotic use. Baseline demographic and clinical data including age, sex, and cause of admission were recorded. Data from patients' medical history including previous antibiotic exposure, previous hospitalizations, corticosteroids exposure.

\subsection{Methods of data collection}

Verbal informed consent was obtained from spouse, parents or caregiver of each subject; thereafter information obtained from Patients' demographic characteristics and medical conditions were collected from electronic sources. The institution's electronic medication administration record was used to determine whether patients received antibiotics or high risk medications (including chemotherapeutic agents, immunosuppressants, and anti-inflammatory drugs), and case files were entered into a semi-structured close-ended questionnaire.

\subsection{Specimen collection and analysis}

Tracheal aspirate, sputum, blood and urine specimens were collected from all recruited patients for microscopy, culture and sensitivity. Specimens were collected using aseptic technique to prevent contamination. For optimal results, specimens were collected in clean sterile, wide bore containers. The samples were collected from patients who had spent at least $72 \mathrm{~h}$ in ICU. Isolation of Acinetobacter was performed on blood agar and Herellea agar and identification of clinical isolates was performed by classical bacteriological techniques (direct examination, biochemical test of orientation). Cultural characteristics observed after an incubation at $36{ }^{\circ} \mathrm{C}$ for 24 hours. The color of colony was pale lavender. The colonies are circular, convex, smooth, and opaque with entire margins of 1 to $2 \mathrm{~mm}$ in diameter.

\section{Data analysis}

All data were analyzed using the Statistical Package for the Social sciences (SPSS) version 18.0. Data were presented as frequency (\%) for qualitative parameters or mean \pm SD for quantitative variables. Univariate analysis was performed to determine variables potentially associated with Acinetobacter infection., such as demographics, blood transfusion in ICU, previous antibiotic and corticosteroid exposure, previous surgery, previous infection, parenteral feeding, and previous ICU hospitalization and experiencing invasive procedures (placement or performance of arterial catheter, abdominal drainages, central venous catheter, mechanical ventilation, nasogastric tube, peripheral vein catheter, pulmonary artery catheter, thoracic drainage, or urinary catheter). Statistical significance was set at 5\%. A logistic regression was conducted to identify factors independently associated with Acinetobacter infection.

\section{Results}

A total of 160 patients were recruited into the study over a period of 9 months, from Aug. 2016 to April. 2017. The age of the patients range from 12 to 83 years. Majority of the patients (31.67\%) were falling in 41- 55 years age group, while the 10-25 year age group constituted the least age group (10.56\%). There were 91 males(56.9\%), and $69(43.1 \%)$ females, giving a male to female ratio of 1.3:1. One hundred twenty patients $(75 \%)$ of the patients were admitted from the emergency department (ER). while the rest were from other wards in the hospital. On the other hand the majority of the cases about 39\% of the admitted cases are having accidents and almost $64 \%$ of them had past history of hospitalization. (Table 1)

Table (1): Represents socio-demographic Characteristics of the selected sample ( $\mathrm{n}=160)$

\begin{tabular}{|c|c|c|c|}
\hline Variable & Category & Frequency & $\%$ \\
\hline Sex & Male & 91 & $56.9 \%$ \\
\hline \multirow{4}{*}{ Age in Years } & $10-25$ & 19 & $10.56 \%$ \\
\hline & $41-55$ & 57 & $31.67 \%$ \\
\hline & $56-70$ & 42 & $23.33 \%$ \\
\hline & $71-85$ & 30 & $16.67 \%$ \\
\hline \multirow{3}{*}{ Causes of admission } & Chronic illnesses & 58 & $36.25 \%$ \\
\hline & Surgical operations & 39 & $24.38 \%$ \\
\hline & Accidents & 63 & $39.38 \%$ \\
\hline \multirow[t]{2}{*}{ Previous hospitalization } & Yes & 102 & $63.75 \%$ \\
\hline & No & 58 & $36.25 \%$ \\
\hline
\end{tabular}


Risk Factors for Acinetobacter infections in the Intensive Care Unit at King Khalid Hospital- ..

46 cases $(28.75 \%)$ were detected positive for various microbial agents in terms of Acinetobacter, Pseudomonas, E-coli, staphylococci, Klebsiella pneumonia, Fungus and others. Within the 46 positive patients, $32(69.57 \%)$ had accidents. Acinetobacter spp was isolated in $19(11.88 \%)$ patients. It was isolated from tracheal secretions in 7 (36.8\%), followed by sputum 5(26.32\%), wounds 3(15.79\%), central venous line (CVL) 2 (10.53 $\%)$, blood $1(5.26 \%)$, and urine $1(5.26 \%)$ as displayed in figure (1).

Figure (1) displayed the sites from where the specimens were extracted among the positive cases $(\mathrm{n}=19)$

\section{Sites for extracted specimens}

$\begin{array}{lll}\square \text { blood } & \text { urine } & \text { central venous line } \\ \square \text { wounds } & \text { sputum } & \text { tracheal secretions }\end{array}$

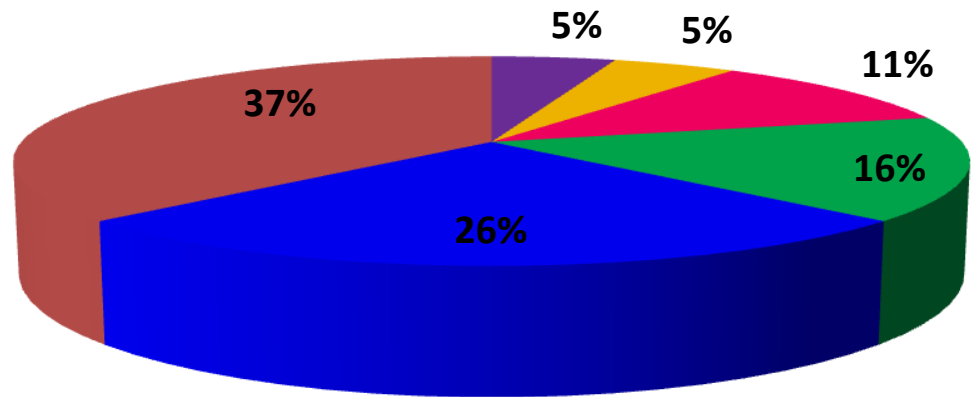

Table (2): shows the univariate analysis of risk factors related to subjects' characteristics.

\begin{tabular}{|c|c|c|c|c|}
\hline Variable & Parameters & $\begin{array}{c}\text { + ve cases for all types of } \\
\text { bacteremia } \\
(n=46)\end{array}$ & $\begin{array}{c}\text { Free of infection/ } \\
\text { colonization } \\
\text { (- ve cases) } \\
\mathrm{N}=114\end{array}$ & $P$ - Value \\
\hline Age & in years & $61.6 \pm 15.4$ & $46.9 \pm 12.1$ & 0.865 \\
\hline \multirow[t]{2}{*}{ Sex } & Male & $28(60.87 \%)$ & $77(67.54 \%)$ & \multirow[b]{2}{*}{0.940} \\
\hline & Female & $18(39.13 \%)$ & $37(32.47 \%)$ & \\
\hline \multirow{9}{*}{$\begin{array}{l}\text { Underlying illness } \\
\text { (Causes of admission) }\end{array}$} & $\mathrm{DM}$ & $29(63.04 \%)$ & $42(36.84 \%)$ & 0.772 \\
\hline & $\begin{array}{c}\text { Cardio-vascular/ blood } \\
\text { disorders }\end{array}$ & $28(60.87 \%)$ & $13(11.40 \%)$ & $0.001^{*}$ \\
\hline & Respiratory disorders & $32(69.57 \%)$ & $19(16.67 \%)$ & $0.031 *$ \\
\hline & Malignancy & $26(56.52 \%)$ & $49(42.98 \%)$ & $<0.001 *$ \\
\hline & Urinary system disorders & $21(45.65 \%)$ & $46(40.35 \%)$ & 0.610 \\
\hline & $\begin{array}{c}\text { Central nervous system } \\
\text { disorders }\end{array}$ & $30(65.22 \%)$ & $67(58.77 \%)$ & 0.056 \\
\hline & Accidents / traumas & $33(71.74 \%)$ & $30(26.32 \%)$ & $0.011 *$ \\
\hline & Surgical cases & $22(47.83 \%)$ & $17(14.91 \%)$ & $0.000 *$ \\
\hline & Others & $18(39.13 \%)$ & $51(44.74 \%)$ & 0.322 \\
\hline \multirow[t]{2}{*}{ Previous hospitalization } & Yes & $38(82.61 \%)$ & $52(45.61 \%)$ & \multirow[t]{2}{*}{$0.001 *$} \\
\hline & No & $8(17.39 \%)$ & $62(54.39 \%)$ & \\
\hline \multirow{2}{*}{$\begin{array}{ll}\text { Previous } & \text { antibiotics } \\
\text { exposure } & \end{array}$} & Yes & $40(86.96 \%)$ & $98(85.96 \%)$ & \multirow[t]{2}{*}{$0.012 *$} \\
\hline & No & $6(13.04 \%)$ & $16(14.04 \%)$ & \\
\hline \multirow{2}{*}{$\begin{array}{l}\text { Receipt of any one of the } \\
\text { invasive procedures }\end{array}$} & Yes & $40(86.96 \%)$ & $100(87.72 \%)$ & \\
\hline & No & $6(13.04 \%)$ & $14(12.28 \%)$ & \\
\hline
\end{tabular}


Risk Factors for Acinetobacter infections in the Intensive Care Unit at King Khalid Hospital- ..

Table 3 shows risk factors related to prior antimicrobial therapy. The average number of prior antimicrobials used was 3.8 in the positive cases of Acinetobacter and 2.7 in negative patients $(\mathrm{P}<0.001)$.

Table (3): Shows risk factors related to prior antimicrobial therapy

\begin{tabular}{|l|c|c|c|c|c|}
\hline Parameters & $\begin{array}{c}\text { + ve cases for all } \\
\text { types of bacteremia } \\
(\mathbf{n = 4 6})\end{array}$ & $\begin{array}{c}\text { Free of infection/ } \\
\text { colonization } \\
\text { (- ve cases) } \\
\mathbf{N = 1 1 4}\end{array}$ & $\begin{array}{c}\text { Odds } \\
\text { Ratio }\end{array}$ & $\mathbf{9 5 \%}$ CI & $\boldsymbol{P}$-value \\
\hline $\begin{array}{l}\text { means } \pm \text { standard deviation of } \\
\text { prior exposure to antibiotics }\end{array}$ & $2.7 \pm 1.1$ & $3.8 \pm 1.4$ & 2.09 & $1.60-2.74$ & $<0.001$ \\
\hline
\end{tabular}

\section{Risk factors related to recent invasive procedures and presence of invasive devices}

As shown in table (4) receipt of any one of the invasive procedures within $48 \mathrm{~h}$ of the date of a positive-culture for positive patients or the date of discharge from the ICU for the negative bacteremic patients, was a significant risk factor for Acinetobacter spp. (odds ratio $=3.72 ; 95 \%$ CI 1.45-10.24; $P=0.007$ ). Patients in whom either an arterial catheter or a central venous catheter was inserted, were at risk of acquiring Acinetobacter infection. Among the inserted invasive devices, central venous catheter, and thoracic drainage catheter/tube were significant risk factors. Patients in whom an endotracheal tube was maintained developed Acinetobacter infection significantly more than those who were switched to a tracheostomy tube.

Table (4): shows univariate analysis of risk factors related to invasive procedures $(n=160)$

\begin{tabular}{|l|c|c|c|c|c|}
\hline Parameters & $\begin{array}{c}\text { + ve cases for all types of } \\
\text { bacteremia } \\
(\mathbf{n = ~ 4 6 )}\end{array}$ & $\begin{array}{c}\text { Free of infection/ } \\
\text { colonization } \\
\text { (- ve cases) } \\
\mathbf{N = 1 1 4}\end{array}$ & $\begin{array}{c}\text { Odds } \\
\text { Ratio }\end{array}$ & $\mathbf{9 5 \%}$ CI & P-value \\
\hline $\begin{array}{l}\text { Recent or presence of } \\
\text { invasive procedure }\end{array}$ & $37(80.4 \%)$ & $107(93.86 \%)$ & 3.72 & $1.45-10.24$ & 0.007 \\
\hline Arterial catheter & $4(8.7 \%)$ & $16(14.04 \%)$ & 3.35 & $1.13-11.10$ & 0.030 \\
\hline Central venous catheter & $6(13.04 \%)$ & $29(25.44 \%)$ & 4.26 & $2.08-13.34$ & $<0.001$ \\
\hline Abdominal drainages & $1(2.17 \%)$ & $5(4.39 \%)$ & - & - & - \\
\hline Thoracic drainage & $0(0 \%)$ & $2(1.75 \%)$ & - & - & - \\
\hline Nasogastric tube & $18(39.13 \%)$ & $11(9.65 \%)$ & 0.47 & $0.21-1.05$ & 0.064 \\
\hline Urinary catheter & $11(23.91 \%)$ & $17(14.91 \%)$ & 1.38 & $0.61-3.11$ & 0.443 \\
\hline Peritoneal dialysis & $2(4.35 \%)$ & $0(0 \%)$ & - & - & - \\
\hline Other procedures & $3(6.52 \%)$ & $7(6.14 \%)$ & 1.39 & $0.44-4.41$ & 0.574 \\
\hline
\end{tabular}

Acinetobacter infection was increased significantly in patients with endotracheal intubation, patients with wounds, and in patients that undergoing invasive procedures as presented in table(5).

Table (5): Multivariate analysis of risk factors for Acinetobacter baumannii.

\begin{tabular}{|l|c|c|c|c|}
\hline & OR & $95 \%$ CI & Wald statistic & $P$-value \\
\hline Endotracheal intubation & 2.759 & $0.919-8.281$ & 3.275 & 0.007 \\
\hline Wounds (surgical or traumatic) & 6.674 & $2.282-19.521$ & 12.016 & 0.001 \\
\hline Central venous line (CVL) & 4.162 & $2.197-16.049$ & 4.168 & 0.011 \\
\hline Blood transfusion in ICU & 2.106 & $0.766-5.792$ & 2.083 & 0.149 \\
\hline Urinary catheterization & 2.142 & $0.811-5.681$ & 2.120 & 0.090 \\
\hline
\end{tabular}

\section{Discussion}

The incidence of Acinetobacter infection, which develops as a result of colonization, is increasing through widespread dissemination of the pathogen, and further colonization. ${ }^{1}$ In recent years , Acinetobacter has become an important pathogen especially in the intensive care units (ICUs). A considerable proportion of critically ill patients acquire an infection during their stay in the ICUs, and the frequency of these infections varies considerably in different populations and clinical settings. Patients admitted to ICU have been shown to be at particular risk of acquiring nosocomial infection with a prevalence rate as high as $30 \%{ }^{8}$ Various studies using different methodologies have analyzed risk factors associated with acquisition of Acinetobacter infections. Most of them have addressed factors that influence the risk of infection in terms of longer hospital stay, respiratory tract infections, and antibiotic use before infection. ${ }^{9}$

This study identified four main risk factors for hospital-acquired A. baumannii resistant infection. Consistent with other studies, a longer hospital stay prior to infection, exposure to invasive procedures, and antibiotic use before infection and chronically ill patients were all significant predictors of Acinetobacter infection. ${ }^{10,11,4}$ High rate of Acinetobacter spp. infection among patients with respiratory tract disorders may be explained in part by high levels of contamination on respirators and suctioning equipment, particularly in ICUs, which may lead to environmental reservoirs of resistant strains. This finding highlights the importance of 
environmental hygiene for preventing Acinetobacter and other infections in the respiratory tract, especially for ventilated patients. ${ }^{12}$

The results of this study confirm what some other studies have shown, that the length of hospital stay and antibiotic use prior to infection are significantly associated with increased risk of acquiring the Acinetobacter infection. In the current study, Acinetobacter Spp. accounted for almost $12 \%$ of nosocomial infection in ICU. This prevalence is near to similar studies carried out by Joly-Juillon ${ }^{13}$ who reported $9 \%$ and Ugochukwu et $\mathrm{al}^{14}$ who reported $14 \%$, and higher than Chang et $\mathrm{al}^{15}$ who reported $4.6 \%$. The majority of positive samples in this study were isolated from the respiratory tract, this finding was consistent with the studies carried out by Nathens et $\mathrm{al}^{16}$, and Ugochukwu et al. ${ }^{14}$ This high rate of recovery from the respiratory tract may be due to the invasive procedures that are carried out during process of maintaining airway.

In this study, the recovery rate of Acinetobacter Spp. from the urinary tract was $5.71 \%$, this was slightly higher than $1.6 \%$ rate reported by Reddy et el. ${ }^{17}$, and $1 \%$ as reported by Ugochukwu et al. ${ }^{14}$ who suggested that this finding confirms the popular report that Acinetobacter is no longer a common uropathogen. The incidence of Acinetobacter blood stream infection in this study was $5.71 \%$, this is higher than what reported by Michalopoulos A and Falagas ${ }^{18}$ who reported $2 \%$, and Ugochukwu et al. ${ }^{14}$ who reported $1.3 \%$ incidence, while it was slightly lower than Lautenbach et al. ${ }^{19}$ who reported $8.8 \%$ incidence in blood.

In the present study, Acinetobacter infection were significantly higher in the patients with surgical operations, and previous hospitalization, patients underlying chronic diseases, and patients that experiencing invasive procedures. This was in agree with finding of Amini et al. ${ }^{20}$ In contrast, in the current study it was concluded that there was no significant differences in relation to patients' ages, and some cases with chronic diseases, this result coincided with what was reported by

\section{Conclusion and Recommendation}

Acinetobacter spp. now account for a substantial proportion of endemic nosocomial infections. Emerging infections due to strains of Acinetobacter spp. in the intensive care unit (ICU) is a therapeutic concern for clinicians worldwide. Acinetobacter infection was increased significantly in patients with old ages, and in patients with chronic underlying diseases. Risk factors for Acinetobacter colonization and infection include prolonged length of hospital stay, mechanical ventilation, central venous catheterization, urinary catheterization, prior exposure to antimicrobials, greater severity of illness, surgery, and receipt of invasive procedures..

To prevent the occurrence and transmission of this organism in the ICU, infection control measures are essential. Measures described in the clinical trials include hand disinfection using either alcohol hand gel or chlorhexidine and contact isolation using glove, gown, and barrier precautions. In most circumstances, however, these two measures alone may not be sufficient. Specialized infection control measures are therefore needed. Moreover, knowledge of these risk factors will allow recommendations for preventive and therapeutic guidelines for the patients admitted in the ICUs.

\section{Acknowledgments}

I am indebted to many colleagues especially Prof. Hussain and Dr. Ali Hamid for their valuable contribution in analyzing specimens as well as reviewing the manuscript. Thanks are also due to Mrs. Tressita and Mrs. Janete, for the data collection, and Dr. Ghada Moh. for her technical support in the preparation of this manuscript.

\section{References}

[1]. Sultat R, Charurat S and Termkiat K: Acinetobacter infection in the ICU. J Infect Dis Antimicrob; 2005; 22(2);77-92.

[2]. Maragakis L, Perl TM: Acinetobacter baumannii: epidemiology, antimicrobial resistance, and treatment options. Clinical infectious diseases. 2008, 46 (8): 1254-1263.

[3]. Playford EG, Craig JC, Iredell JR: Carbapenem-resistant Acinetobacter baumannii in intensive care unit patients: risk factors for acquisition, infection and their consequences. The Journal of hospital infection. 2007, 65 (3): 204-211.

[4]. Jang TN, Lee SH, Huang CH, Lee CL, Chen WY: Risk factors and impact of nosocomial Acinetobacter baumannii bloodstream infections in the adult intensive care unit: a case-control study. The Journal of hospital infection. 2009, 73 (2): 143-150.

[5]. Lee S, Kim NJ, Choi S, Kim TH, Chung J, Woo J, Ryu J, Kim YS: Risk factors for acquisition of imipenem-resistant Acinetobacter baumannii: a case-control study. Antimicrobial agents and chemotherapy. 2004, 48 (1): 224-228.

[6]. Shih M, Lee N, Lee H, Chang C, Wu C, Chen P, Ko N, Ko W: Risk factors of multidrug resistance in nosocomial bacteremia due to Acinetobacter baumannii: a case-control study. Journal of microbiology, immunology and infection. 2008,41 (2): $118-123$.

[7]. Valencia R, Arroyo LA, Conde M, Aldana JM, Torres M, Fernndez-Cuenca F, Garnacho-Montero J, Cisneros JM, Ortz C, Pachn J, Aznar J: Nosocomial outbreak of infection with pan-drug-resistant Acinetobacter baumannii in a tertiary care university hospital. Infection control and hospital epidemiology. 2009, 30 (3): 257-263.

[8]. Wareham DW, Bean DC, Khanna P, Hennessy EM, Krahe D, Ely A, Millar M: Bloodstream infection due to Acinetobacter spp: epidemiology, risk factors and impact of multi-drug resistance. European journal of clinical microbiology \& infectious diseases. 2008, 27 (7): 607-612.

[9]. Erbay A, Idil A, Gzel MG, Mumcuoğlu I, Balaban N: Impact of early appropriate antimicrobial therapy on survival in Acinetobacter baumannii bloodstream infections. International journal of antimicrobial agents. 2009, 34 (6): $575-579$. 
[10]. Metan G, Sariguzel F, Sumerkan B: Factors influencing survival in patients with multi-drug-resistant Acinetobacter bacteraemia. European journal of internal medicine. 2009, 20 (5): 540-544.

[11]. Hartzell JD, Kim AS, Kortepeter MG, Moran KA: Acinetobacter pneumonia: a review. MedGenMed. 2007, 9 (3): 4-4.

[12]. Townsend S, Vender JS, Zimmerman JL, Vincent JL: Surviving Sepsis Campaign: international guidelines for management of severe sepsis and septic shock: 2008. Critical care medicine. 2008, 36 (1): 296-327.

[13]. 13-Joly-Guillou ML: Clinical impact and pathogenecity of Acinetobacter. Clin. Microb. Infect; 2005; 11(1): 868-73.

[14]. Ugochukwu NV, Adetona FS, Adeala F, Ajani BR and Olusanya O: Nosocomial Acinetobacter infections in Intensive Care Unit. Am. J. Infect Dis; 2013; 9(2): 40-45.

[15]. Chang H, Tang C, Hsu Y, Wan L, Chang Y, Lin C, Tseng Y, Lin Y, Sheu J, Lin C, Chang Y, Ho M, Lin C, Ho C, Lai C: Nosocomial outbreak of infection with multidrug-resistant Acinetobacter baumannii in a medical center in Taiwan. Infection control and hospital epidemiology. 2009, 30 (1): 34-38.

[16]. Nathens AB, Rivara FP, Mack CD, Rubenfeld GD, Wang J, Jurkovich GJ, Maier RV: Variations in rates of tracheostomy in the critically ill trauma patient. Critical care medicine. 2006, 34 (12): 2919-2924.

[17]. Reddy, T., Chopra, T., Marchaim, D., Pogue, J., Alangaden, G., Salimnia, H., Boikov, D., Navon-Venezia, S., Akins, R., Selman, P., Dhar, S., \& Kaye, K. Trends in Antimicrobial Resistance of Acinetobacter baumannii Isolates from a Metropolitan Detroit Health System Antimicrobial Agents and Chemotherapy, 2010; 54 (5), 2235-2238.

[18]. Michalopoulos A and Falagas M : Therapeutic Strategies For Acinetobacter bauminnii infections. Eur. Infect. Dis; 2007; 4(1): 125 27.

[19]. Lautenbach E, Synnestvedt M, Weiner MG, Bilker WB, Vo L, Schein J, Kim M: Epidemiology and impact of imipenem resistance in Acinetobacter baumannii. Infect Control Hosp Epidemiol. 2009, 30 (12): 1186-1192.

[20]. Amini M, Davati A and Golestanifard M.: Frequency of nosocomial infections with antibiotic resistant strains of Acinetobacter spp. in ICU. Iran J Pathol; 2012; 7(4):241-45. 